\title{
Distribution of Polychlorinated Biphenyls in Different Depths of Soil from a Polluted Area in the People's Republic of China
}

\author{
L. Gao, X. Zhao, M. Zheng, B. Zhang, W. Liu
}

Key Laboratory of Environmental Chemistry and Ecotoxicology, Research Center for Eco-Environmental Sciences, Chinese Academy of Sciences, Post Office Box 2871, Beijing 100085, People's Republic of China

Received: 20 October 2004/Accepted: 14 February 2005

Polychlorinated biphenyls (PCBs) have attained considerable notoriety as ubiquitous environmental contaminants (WHO, 1993). They have been found in all environmental media including water, soil, air and sediment (Chevreuil et al.1998; Backe et al. 2004). The environmental fate, transport and accumulation in the food chains of PCBs have been report (Backe et al. 2004; Bi et al. 2002). Because of non-flammable and chemically inert, PCBs were widely used as dielectrics in transformers and large capacitors during 1929-1970 all over the world. From 1965 to 1974 , the total output of PCBs was 10000 tons while 9000 tons was PCB3 in China. PCB3 is principally used for the impregnant of power capacitor, and 9000 tons of PCB3 can produce about 0.75 million sets of capacitors. Although their industrial production ceased during the eighties in China, the waste transformers and capacitors are still the major source of the pollution of PCBs in the environment.

In 1989, large amounts of waste power capacitors were illegally discharged into an area in east of China, and PCBs residues in this region are still a serious problem. The unexpected routes of human exposure to these highly toxic compounds could increase the level of uncertainty of their risks. The adverse impacts imposed by high concentrations of $\mathrm{PCBs}$ have been arisen the great concern of the Chinese government. The PCBs pollutions in this area have been reported by several investigators (Bi et al. 2002; Meng et al. 2000). The purpose of this work was to study the concentrations, fluxes and transports of the PCBs in the soil from 1989 onward.

\section{MATERIALS AND METHODS}

Samples were collected from a contaminated field in the east of China. The field has not been farmed since 1989. There was no other PCBs pollution source near this area, so it offered an ideal place to study the movement of PCBs in the soil. In order to study the distributions and fluxes of PCBs in different depths of soil, triplicate samples were collected from the surface of soil of $250 \mathrm{~m}^{2}$ in September 2003. The depth of the soil was $20 \mathrm{~cm}$ and sections were $5 \mathrm{~cm}$ for all the soil samples. The major part of the soil was mud with a dark brown color and no visible variations. Each section was stored at $-18^{\circ} \mathrm{C}$ and freeze-dried until 
analysis.

Prior to extraction, $0.5 \mathrm{~g}$ of dried soil were homogenized and spiked with a mixture of internal standards $\left({ }^{13} \mathrm{C}_{12}\right.$ PCBs congeners, Cambridge Isotope laboratories). Then samples were mixed with anhydrous sodium sulfate which had been baked out at $660^{\circ} \mathrm{C}$ to remove residual water and impurity. The mixture were placed in pre-extracted thimbles and extracted in a Soxhlet apparatus with toluene for 24 hours. After the samples were rotary evaporated to $0.1 \mathrm{ml}, 1 \mathrm{ml}$ hexane were added. Then the samples were cleaned by three adsorption columns. The first acidic silica gel columns were prepared by packing a glass column $(15 \mathrm{~mm}$ i.d.) with layers of $10 \mathrm{~g}$ of $44 \%$ acidic silica and a thin layer of sodium sulfate at the top. The columns were cleaned with $50 \mathrm{ml}$ hexane prior to transfer of sample extracts. Samples were then eluted with $70 \mathrm{ml}$ hexane and rotary evaporated to $1 \mathrm{ml}$. The second multilayer silica columns $(15 \mathrm{~mm}$ i.d.) were packed with $1 \mathrm{~g}$ of silica, $2 \mathrm{~g}$ of $10 \% \mathrm{AgNO}_{3}$ silica, $1 \mathrm{~g}$ of silica, $5 \mathrm{~g}$ of $33 \%$ basic silica, $1 \mathrm{~g}$ of silica, $8 \mathrm{~g}$ of $44 \%$ acidic silica, $1 \mathrm{~g}$ of silica and a thin layer of sodium sulfate at the top. The columns were cleaned with $70 \mathrm{ml}$ hexane prior to transfer of sample extracts. Samples were then eluted with $100 \mathrm{ml}$ hexane and rotary evaporated to $1 \mathrm{ml}$. The third basic alumina columns (10 $\mathrm{mm}$ i.d.) were packed with $8 \mathrm{~g}$ of basic alumina and a thin layer of sodium sulfate at the top. The columns were cleaned with $100 \mathrm{ml}$ hexane prior to transfer of sample extracts. Samples were then eluted with $100 \mathrm{ml} 5 \%$ dichloromethane/ hexane and rotary evaporated tol $\mathrm{ml}$. Then the samples were transfer to K-D concentrator and concentrated by means of a rotary evaporator to nearly $500 \mu \mathrm{l}$. And then the samples were concentrated by gentle nitrogen to $50 \mu \mathrm{l}$. The recovery internal standards $\left({ }^{13} \mathrm{C}_{12}\right.$ PCBs Cambridge Isotope laboratories) were added.

All samples were analyzed by an Agilent $6890 \mathrm{GC} / 5973 \mathrm{~N}$ MS by using a $60 \mathrm{~m}$ DB-5 fused-silica column. The $(\mathrm{m} / \mathrm{z})$ recorded in SIM mode. Helium at a flow rate of $1.0 \mathrm{ml} / \mathrm{min}$ was used as gas carrier. Oven temperature was programmed according to the following sequence: injection at $75^{\circ} \mathrm{C}$, was steady for 2 min and then was increased from 50 to $150{ }^{\circ} \mathrm{C}$ at a rate of $15{ }^{\circ} \mathrm{C} / \mathrm{min}$ and then was increased from 150 to $270{ }^{\circ} \mathrm{C}$ at a rate of $2.2^{\circ} \mathrm{C} / \mathrm{min}$. All of the organic solvents used were of pesticide-grade.

\section{RESULTS AND DISSCUSSION}

The recoveries for the PCBs congeners varying between $72.4 \%$ and $85.6 \%$ were determined by adding known amounts of PCBs standards. The analytical of the blanks covered the entire analytical process, and no PCBs were detected in the blanks.

Polychlorinted biphenyls were found in all the soil samples analyzed (shown in Table 1). The sum concentrations of PCBs ranged from $2458 \mathrm{ng} / \mathrm{g}$ to $5644 \mathrm{ng} / \mathrm{g}$ dry weight soil. The three predominated congeners in the soil were PCBs with IUPAC numbers $28,52,105$. The contamination levels were categorized according to five standard class (values were expressed as ng/g of dry wight): low $(\leq 50)$; medium (>50-200); high (200-1000); very high (>1000-10000); 
exceptional $(\geq 10000$ ) (Chevreuil et al.1998). It can be seen from that the sum concentrations of PCBs in all of the sections were very high. The concentrations of PCBs there were significantly higher than those in soil from Wentai (Bi et al, 2002), which was another PCBs pollution area contaminated by capacitors in east of China.

Table 1. Concentrations of PCBs in difference depths of soil (ng/g d.w.).

\begin{tabular}{lllll}
\hline & $0-5 \mathrm{~cm}$ & $5-10 \mathrm{~cm}$ & $10-15 \mathrm{~cm}$ & $15-20 \mathrm{~cm}$ \\
\hline CB28 & 290 & 349 & 353 & 304 \\
CB52 & 130 & 218 & 117 & 115 \\
CB81 & 17 & 12 & 12 & 8.9 \\
CB77 & 67 & 50 & 65 & 63 \\
CB101 & 66 & 89 & 63 & 44 \\
CB123 & 18 & 16 & 16 & 13 \\
CB118 & 3.8 & 82 & 35 & 17 \\
CB114 & 9.2 & 10 & 5.1 & 4.5 \\
CB105 & 248 & 213 & 158 & 156 \\
CB126 & 5.2 & 3.8 & 3.2 & 2.5 \\
CB153 & 42 & 56 & 57 & 33 \\
CB138 & 68 & 74 & 77 & 47 \\
CB167 & 4.9 & 6.8 & 5.6 & 3.0 \\
CB156 & ND & 10 & 9.5 & 7.3 \\
CB157 & ND & 3.5 & 2.8 & 2.4 \\
CB180 & 9.0 & 11 & 11 & 6.1 \\
CB209 & 0.14 & 0.51 & 0.35 & 0.14 \\
$\sum$ TriCB & 424 & 1619 & 1516 & 728 \\
$\sum$ TetraCB & 2058 & 2074 & 2339 & 1224 \\
$\sum$ PentaCB & 1384 & 1663 & 457 & 409 \\
$\sum$ HexaCB & 216 & 240 & 226 & 75 \\
$\sum$ HeptaCB & 29 & 72 & 74 & 18 \\
$\sum$ OctaCB & 5.0 & 13 & 13 & 3.6 \\
$\sum$ NonaCB & 0.70 & 1.8 & 1.5 & 0.49 \\
$\sum$ DecaCB & 0.14 & 0.51 & 0.35 & 0.14 \\
$\sum$ PCB & 4117 & 5644 & 4626 & 2458 \\
\hline ND 0.012 & & & &
\end{tabular}

$\mathrm{ND}<0.012 \mathrm{ng} / \mathrm{g}$

The maximum concentration was founded in the section $5-10 \mathrm{~cm}$. This may reflect the actual input at the time. With the outgassing and depositing of the PCBs, they were transferred to other sections. In the $5-10 \mathrm{~cm}$ section, the mixture was dominated by tri- to pentachlorinated congeners (shown in Figure.1). Although the PCB3 was the main source of the PCBs pollution in this area, the PCBs trends generally didn't follow the pattern of the original commercial PCB3. The composition of trichlorinated congeners contributed about 28 percent of the sum PCBs in this section, while the composition of trichlorinated congeners contributed about 80 percent of the sum PCBs in the original commercial PCB3. The biodegradation probably was the major way for removing $\mathrm{PCBs}$ in this section. Several studies in the general literature have demonstrated that the 


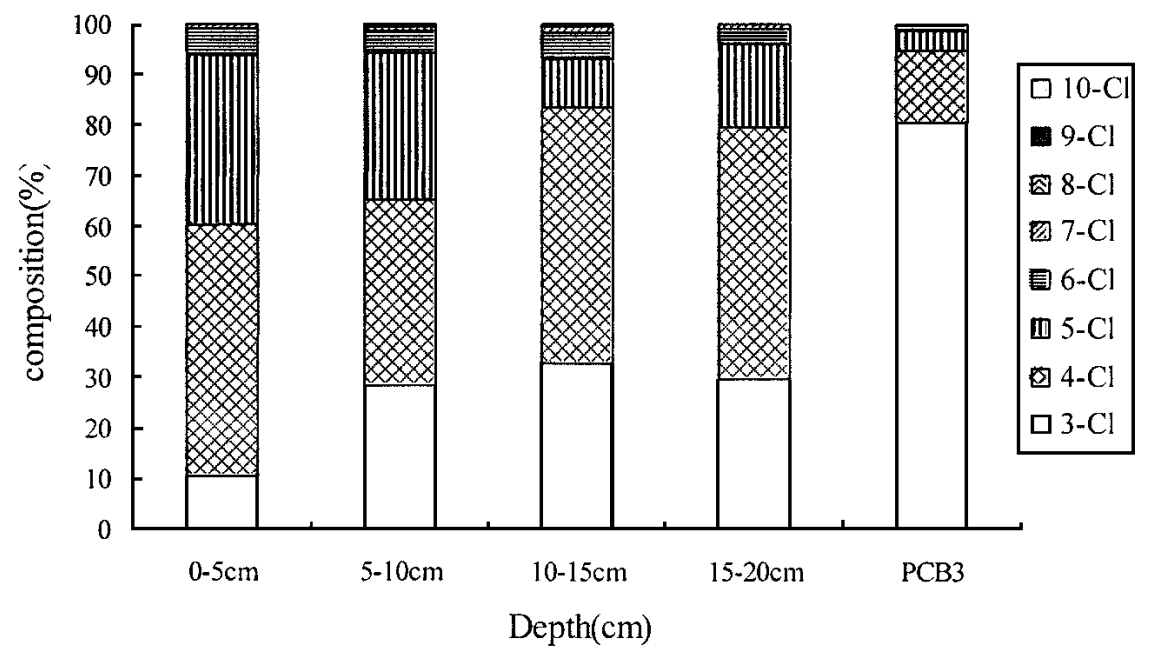

Figure.1 Composition of PCB congeners in different depths soil and PCB3

viability of PCBs transformation via biodegadation under both aerobic and anaerobic conditions (US EPA, 2000b). Biodegradation causes the disappearance of the lower chlorinated PCBs, and the degradation decrease with increasing chlorination (Furukawa, 1978).

In the top surface layer, the mixture was dominated by tetra- and pentachlorinated congeners. This may reflect outgassing of the lighter congeners, which dominate the vapour phase mixture of PCBs in the contemporary atmosphere (Alcock et al 1993, Halsall et al 1993). The composition of trichlorinated biphenyls contributed the least about 10 percent of the total PCBs in this section. There are several possible reasons for that. First, trichlorinated congeners were subject to post-depositional transportation down the soil, either by chemical diffusion, rainfall dissolution. Another reason is that the trichlorinated congeners were susceptible to accumulate in the vegetation. It was reported (Bohme et al. 1999) that vapor-to-plant portioning is most important for trichlorinated biphenyls. The last reason is that the lower chlorinated congeners were subject to evaporation than highly chlorinated PCBs. Dunnivant and Elzermqn (1992) determined the Henry's Law Constants (HLCs) for several PCBs congeners and calculated all HLC of 209 congeners, and found that $-\operatorname{logHLC}$ ranged from 3.215 (PCB50) to 4.186 (PCB169). This shows that highly chlorinated PCBs have lower HLC than lower chlorinated PCBs. Additionally, it was worth to be mentioned that the top section was the only one that could not detected PCB156 and PCB157 among the 4 sections. Photolysis of PCBs on surface soil may occur. It was reported (Brown et al. 1995) that PCB 156 exhibiting the highest photolysis rate among the other congeners (half life of $55 \mathrm{~h}$ ).

The mixture was dominated by tri- and tetrachlorinated congeners at the bottom 
$10 \mathrm{~cm}$. It is possible that PCBs were detected partly as a result of post-depositional mobility similar to that discussed by Rapaport (1988). The lower chlorinated congeners are subject to downward by rainfall to this section. So the deeper soil was dominated by tri- and tetrachlorinated species.

The concentrations of sum PCBs were still very high because of their low degradation rate after the soil was contaminated 15 years. The residents were imposed potential risk for considerable contamination by PCBs in the soil. Based on this study it was possible to have an insight of the pattern of PCBs inputs and fluxes in soil. The depths distribution of PCBs may be used as indication of the transformation processes they have undergone after deposition onto the soil surface. Further study of the food chain would help to better characterize environmental contamination from PCBs.

Acknowledgment. This work was supported by National Basic Research Program of China (2003CB415006) and National 863 Project (2002AA641010).

\section{REFERENCES}

Alcock R, Johnston AE, Mcgrath SP, Berrow ML, Jones KC (1993) Long-term changes in the polychlorinated biphenyl (PCB) content of United Kingdom soils. Environ Sci Technol 27:1918-1923

Backe C, Cousins IT, Larsson P (2004) PCB in soils and estimated soil-air exchange fluxes of selected PCB congeners in the south of Sweden. Environ Pollut 128: 59-72

Bi XH, Chu SG, Meng QY, Xu XB (2002) Movement and retention of polychlorinated biphenyls in a paddy field of WenTai area in China. Agr Ecosys Environ 89: 241-252

Bohme F, Welsch-Pausch K, Malachlan MS (1999) Uptake of airborne semivolatile organic compounds in agriculture plants: field measurements of interspecies variability. Environ Sci Technol 33:1805-1813

Brown JF, Frame GM, Olson DR, Webb JL (1995) The sources of PCBs Organohalogen Comp 33:199-204

Bushart S, Bush B, Barnard EL, Bott A (1998) Volatization of extensively dechlorinated PCBs from historically contaminated sediments. Environ Toxicol Chem 17:1927-1933

Chevreuil M, Blancharo M, Teil MJ, Chesterikoff A (1998) Polychlorobiphenyl behavior in the water/sediment system of the Seine river France. Wat Res 32:1204-1202

Dunnivant FM, Elzermqn AW (1992) Quantitative structure-property relationships for aqueous solubilities and Henry's law constants of polychlorinated biphenyls. Envion Sci Technol 26:1567-1573

Furukawa K, Tonomura A, Kamibazashi A (1978) Effect of chlorine substitution on the biodegradability of polychlorinated biphenyls. Appl Environ Microbiol 32: $223-227$

Halsall C, Burneet V, Clayton P, Davis B, Jones P, Pettit K, Jones KC (1993) PCBs and PAHs in UK urban air. Chemosphere. 26:2185-2197

Hutzinger O, Safe S, Zitko V (1974) The chemistry of PCBs. CRC Press, 
Cleveland, $\mathrm{OH}, 7-39$.

Isosarri P, Pajunen H, Vartiainen T (2002) PCDD/F and PCB history in dated sediments of a rural lake. Chemosphere 47:575-583

Meng QY, Bi XH, Chu SG, Xu XB (2000) Preliminary study of the characterization and distribution of PCB congeners between vapor phase and aerosols in polluted area. Chinese J Environ Chem 19:501-506

Rapaport RA, Eisenreich SJ (1988) Historical atmospheric inputs of high molecular weight chlorinated hydrocarbons to eastern North America. Environ Sci Technol 26:1815-1821

World Health Organization (1993) Environmental Health Criteria 140, Polychlorinated biphenyls and terphenyls. World Health Organization, Geneva 